a ciclos menstruais longos e amenorréicos, hirsutismo e ovários policísticos aumentados. A neurotransmissão pode ser também afetada, nos regimes de emagrecimento por restrição calórica, nas situações de exercícios físicos excessivos ou em situações de estresse. Na presença de obesidade, acne, hirsutismo e alteração menstrual, independente da idade ginecológica, a possibilidade de anovulação crônica deve ser investigada de imediato.

Palavras-chave: Adolescência. Hiperandrogenismo. Sangramento uterino disfuncional. Anovulação.

\title{
Avaliação dos Padrões Vasculares Uterino e Placentário no Primeiro Trimestre das Gestações Normal e Patológica
}

Autor: Marcelo Giacobbe

Orientador: Prof. Dr. Luiz Carlos Zeferino

Dissertação de Mestrado apresentada ao Curso de Pós-Graduação em Medicina, área de Tocoginecologia da Faculdade de Ciências Médicas da Universidade Estadual de Campinas para obtenção do Título de Mestre em Medicina, na área de Tocoginecologia, em 4/2/99.

Existem dúvidas e contradições nas informações sobre o padrão vascular útero-placentário no primeiro trimestre da gestação. Com o objetivo de descrever as características vasculares útero-placentárias na gestação até 14 semanas, foi realizado um estudo clínico, descritivo, comparativo, utilizando a dopplervelocimetria com mapeamento em cores endovaginal em 45 mulheres com gestação e 44 com aborto. Estudou-se a quantidade de vasos miometriais, o fluxo interviloso (FIV), os índices de resistência (IR), pulsatilidade (IP), as velocidades sistólica (VS) e diastólica (VD) das artérias miometriais. Para a análise utilizou-se o teste Qui-Quadrado, teste de Wilcoxon e a análise de regressão linear múltipla. A quantidade de vasos miometriais foi menor na gestação que no aborto $(\mathrm{p}<0,001)$. A identificação de FIV foi mais freqüente no aborto $(\mathrm{p}<0,001)$ e a gestação mostrou tendência de uma maior presença de FIV acima de 10 semanas de idade gestacional. As médias dos IR e IP da gestação foram maiores que as do aborto $(\mathrm{p}<0,03)$. Observou-se uma diminuição dos IR e IP nas artérias uterinas e arqueadas com a progressão da idade gestacional em ambos os grupos. A VS da uterina aumentou na gestação e esteve constante no aborto ao longo do primeiro trimestre. A VD da uterina apresentou aumento progressivo em ambos os grupos. As características vasculares observadas na gestação mostraram-se diferentes das do aborto na avaliação pela dopplervelocimetria com mapeamento em cores com evidências de haver uma facilitação ao fluxo sangüíneo associado ao processo de falência gestacional.

Palavras-chave: Ultra-sonografia em obstetrícia. Aborto. Gravidez normal. Dopplervelocimetria. Endometrail de Mulheres em Ciclos Estimulados para Fertilização In Vitro

Autor: Daniella Spilborghs Castellotti

Orientador: Prof. Dr. Edmund Chada Baracat

Dissertação apresentada à Escola Paulista de Medicina - Universidade Federal de São Paulo para obtenção do título de Mestre em Ginecologia, em 25/02/99.

Objetivo: Avaliar a perfusão sanguínea uterina de mulheres submetidas a fertilização in vitro, como parâmetro prognóstico da receptividade endometrial. Pacientes e Métodos: Estudaram-se, prospectivamente, 20 mulheres com idade inferior a 38 anos, $\mathrm{FSH}<15 \mathrm{mUI} / \mathrm{ml}$ e $\mathrm{E} 2<60 \mathrm{pg} / \mathrm{ml}$ no $3^{\circ}$ dia do ciclo menstrual, com cavidade uterina normal, nãofumantes e hígidas A indicação para FIV / ET foi fator masculino (45\%), fator tubário (30\%), idiopático (15\%) e endometriose (10\%). O mesmo protocolo de indução da ovulação foi utilizado em todos os ciclos. No dia da hCG, realizou-se ultra-sonografia transvaginal com dopplervelocimetria dos ramos ascendentes das artérias uterinas, das artérias arqueadas e das arteríolas espiraladas. Avaliou-se, também, o padrão subjetivo de fluxo intramiometrial. Apenas as pacientes que apresentavam eco endometrial com espessura $>7 \mathrm{~mm}$ e padrão trilaminar foram incluídas. Transferiram-se três ou quatro embriões de excelente qualidade avaliados pelo cumulative embryo score (CES). Dividiram-se as pacientes de acordo com a presença (grupo I) ou não de gravidez (grupo II).

Resultados: O IP e o IR das artérias uterinas foi significantemente menor no grupo I em relação ao grupo II. O IP e o IR das artérias arqueadas e espiraladas foram menores no grupo I em relação ao grupo II, entretanto, esta diferença não foi significante. Não observamos diferença no padrão subjetivo de fluxo entre os 2 grupos. Não ocorreu gravidez quando o IP das artérias uterinas foi maior que 3,00. A taxa de implantação foi de $20,2 \%$ e, a de gravidez, de $50 \%$.

Conclusão: O fluxo sanguíneo uterino desempenha relevante papel no processo de implantação em ciclos induzidos de fertilização in vitro.

Palavras Chaves: Fertilização in vitro. Infertilidade. Endométrio. Dopplervelocimetria. 